Erratum

\title{
Erratum to "Nanopigmented Acrylic Resin Cured Indistinctively by Water Bath or Microwave Energy for Dentures"
}

\author{
L. S. Acosta-Torres $\mathbb{D}^{1}{ }^{1}$ M. C. Arenas-Arrocena $\left(\mathbb{D},{ }^{1}\right.$ R. E. Nuñez-Anita, ${ }^{2}$ \\ F. H. Barceló-Santana, ${ }^{3}$ C. A. Álvarez-Gayosso, ${ }^{3}$ J. Palacios-Alquisira, ${ }^{4}$ \\ J. de la Fuente-Hernández, ${ }^{1}$ Marcos Cajero-Juárez, ${ }^{2}$ and V. M. Castaño ${ }^{5,6}$ \\ ${ }^{1}$ Escuela Nacional de Estudios Superiores, Unidad León, Licenciatura en Odontología, Universidad Nacional Autónoma de México, \\ Boulevard UNAM No. 2011 Predio el Saucillo y el Potrero, GTO, 36969 León, Mexico \\ ${ }^{2}$ Facultad de Medicina Veterinaria y Zootecnia, UMSNH, Km. 9.5 Carretera Morelia-Zinapécuaro, Col. La Palma, 58893 Tarímbaro, \\ MICH, Mexico \\ ${ }^{3}$ Laboratorio de Materiales Dentales, División de Estudios de Posgrado e Investigación, Facultad de Odontología, \\ Universidad Nacional Autónoma de México, Avenida Universidad No. 3000, Colonia Copilco, 04510 México, DF, Mexico \\ ${ }^{4}$ Posgrado de la Facultad de Química, Universidad Nacional Autónoma de México, Avenida Universidad No. 3000, Colonia Copilco, \\ 04510 México, DF, Mexico \\ ${ }^{5}$ Departamento de Ingeniería Molecular de Materiales, Centro de Física Aplicada y Tecnología Avanzada, Universidad Nacional \\ Autónoma de México, Campus Juriquilla, Boulevard Juriquilla No. 3001, 76230 Juriquilla, QRO, Mexico \\ ${ }^{6}$ Centro de Tecnología Avanzada, (CIATEQ), av. El Retablo 150, Qro, 76150 Querétaro, Mexico
}

Correspondence should be addressed to M. C. Arenas-Arrocena; mcaa05@gmail.com

Received 20 March 2019; Accepted 25 March 2019; Published 14 July 2019

Copyright (c) 2019 L. S. Acosta-Torres et al. This is an open access article distributed under the Creative Commons Attribution License, which permits unrestricted use, distribution, and reproduction in any medium, provided the original work is properly cited.

In the article titled "Nanopigmented Acrylic Resin Cured Indistinctively by Water Bath or Microwave Energy for Dentures" [1], there was an error in Figure 2, where Figure 2(a) was mistakenly duplicated with Figure 3(a), due to a production error. The correct figure is shown below. In addition, the name of the corresponding author was given incorrectly as M. C. Arenas. The author's name should have been written as M.C. Arenas-Arrocena. The revised authors' list is shown above. 


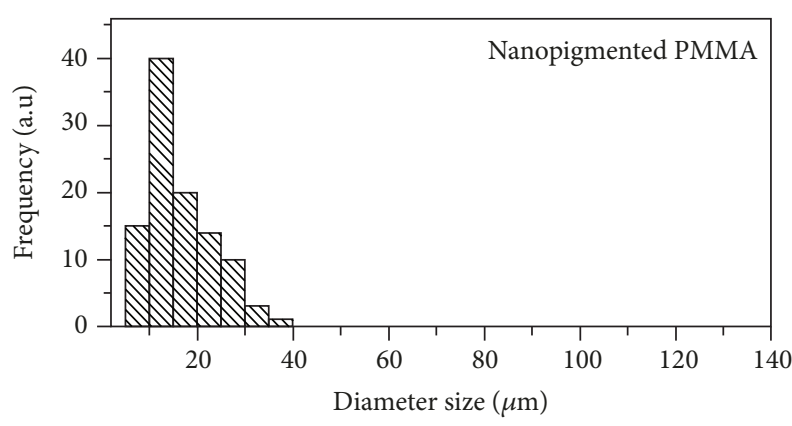

(a)

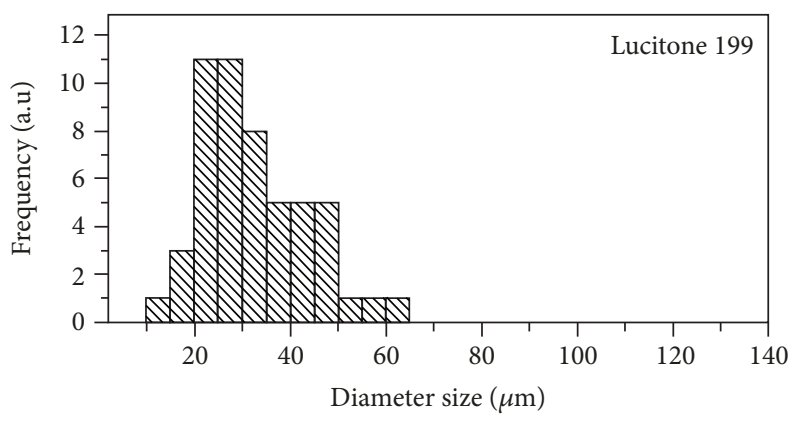

(b)

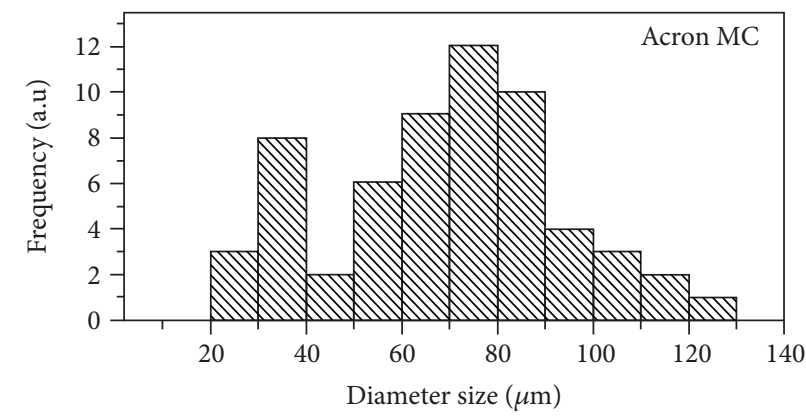

(c)

FIgURE 2: Statistical particle size distribution of (a) nanopigmented PMMA compared to the commercial acrylic resins: (b) Lucitone 199 and (c) Acron MC.

\section{References}

[1] L. S. Acosta-Torres, M. C. Arenas, R. E. Nuñez-Anita et al., "Nanopigmented acrylic resin cured indistinctively by water bath or microwave energy for dentures," Journal of Nanomaterials, vol. 2014, Article ID 198572, 8 pages, 2014. 


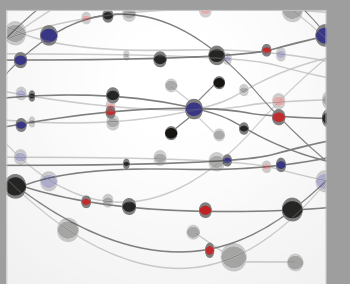

The Scientific World Journal
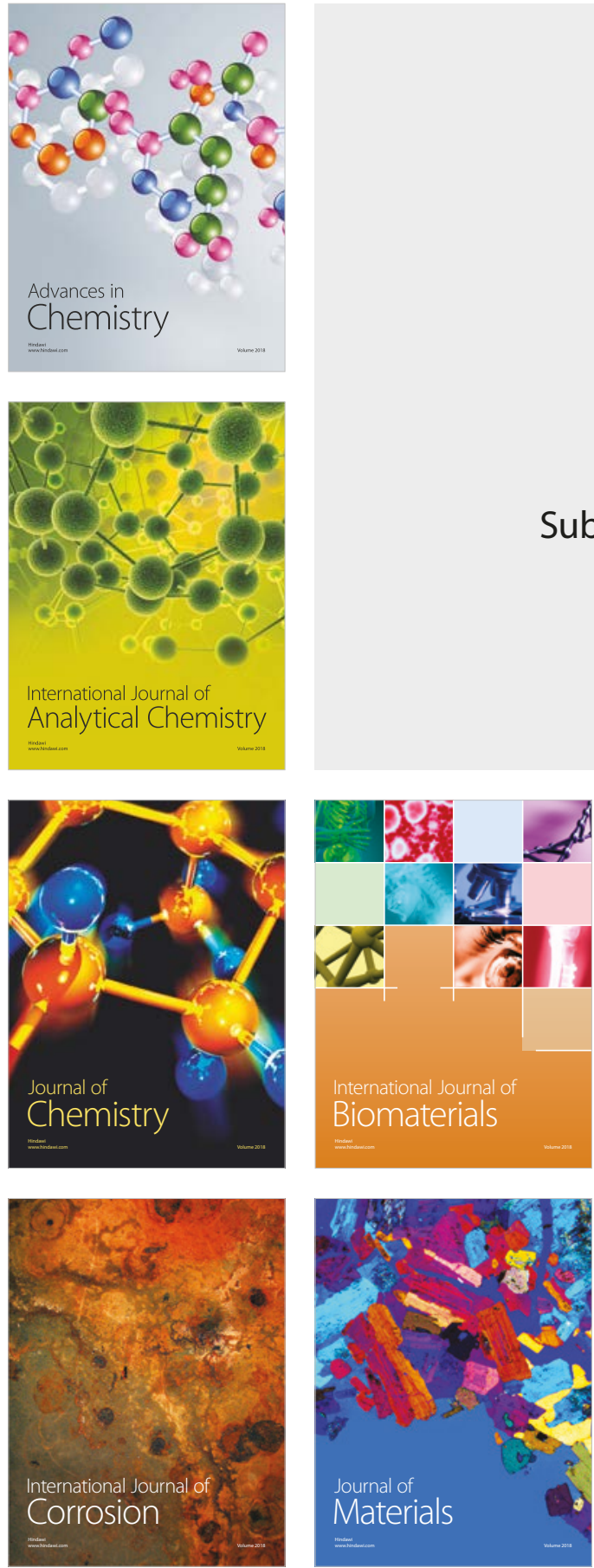

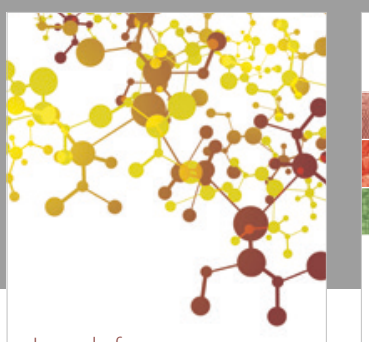

Journal of

Applied Chemistry
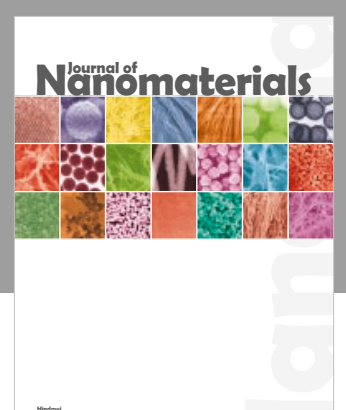

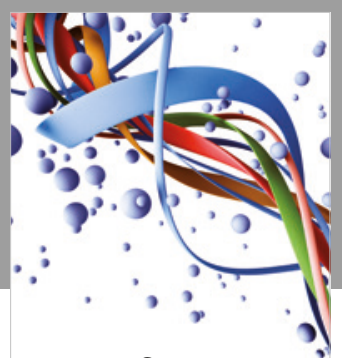

Scientifica

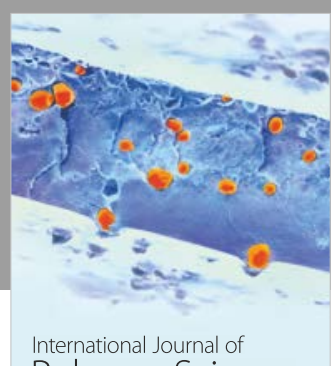

Polymer Science

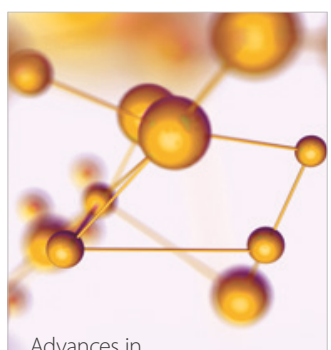

Physical Chemistry
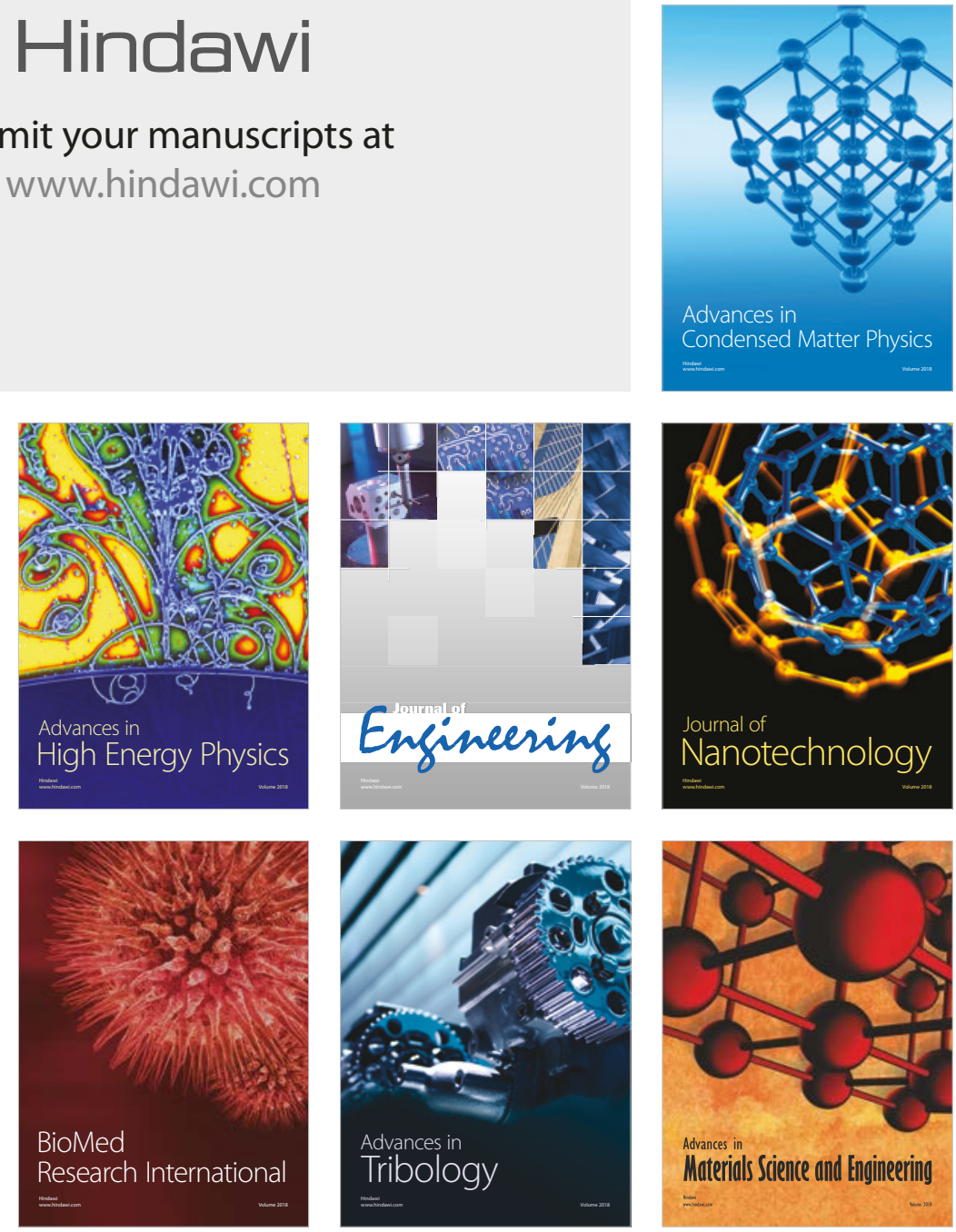